\title{
Photocatalytic Degradation of Vat Green 03 Textile dye, Using the Ferrihydrite-Modified Diatomite with $\mathrm{TiO}_{2} / \mathrm{UV}$ Process
}

\author{
W. REZIG* and M. HADJEL \\ Faculty of Chemistry, University of Sciences and the Technology of Oran Mohamed Boudiaf \\ Algeria, BP 1505 El M'naouerBir El Djir 31016 Oran , 31016 Bir El Djir Oran, Oran, Algeria. \\ ${ }^{*}$ Corresponding author E-mail: walidrzg @ gmail.com \\ http://dx.doi.org/10.13005/ojc/300310
}

(Received: June 25, 2014; Accepted: August 04, 2014)

\begin{abstract}
This work is a study of the photodegradation ( photocatalytic degradation ) of a dye of the textile industry. The Vat Green 03 textile dye of a chemical structure is $\mathrm{C}_{31} \mathrm{H}_{15} \mathrm{NO}_{3}$ as a function of $\mathrm{pH}$, Titanium dioxide concentration and dye concentration in the study with dyestuff were led by lamp UV of trans-illuminator using the titanium dioxide $\mathrm{TiO}_{2}$ ( Degussa P25) like catalyst with a co-adsorbent, which is a rock formed primarily by the accumulation of frustules of diatoms called « diatomite or Kieselguhrs» in the layer of Sig having the advantage of being locally available and less expensive . The diatomite, which will be modified by iron « the deposit of ferrihydrite on raw diatomite by $\mathrm{FeCl}_{2} .4 \mathrm{H}_{2} \mathrm{O}$ " and $\mathrm{NaOH}$ to increase the specific surface area of this material. Comparison of the results from $x$-ray diffraction ( XRD) show that the raw diatomite has an irregular structure at the modification by ferrihydrite to obtain the principal phases of ferric oxide in kind are, in rule of crystallinity, ferrihydrite, maghemite, akaganeite, magnetite,hematite, goethite, and Schwertmannite increasing .The prepared material of diatomite and ferrihydrite applied for the photodegradation of Vat Green 03 textile dye used a concentration $20 \mathrm{mg} / \mathrm{L}$ with different of $\mathrm{pH}$, and different concentrations from materials, added with $0,02 \mathrm{~g}$ titanium dioxide $\left(\mathrm{TiO}_{2}\right)$ under lamp UV with an agitation. The results of the photocatalytics tests applied from material DMF1 which there was a better colour remove about $97 \%$ at $\mathrm{pH}=4$. The objective of this work it is the elimination of the organic pollutants of industrial wastewater.
\end{abstract}

Key words: photodegradation, textile, dye, $\mathrm{TiO}_{2}$, diatomite, ferrihydrite,lamp UV.

\section{INTRODUCTION}

The objectives of the research were to extract and compare the two methods for extraction of cinnamon's essential oil, to analyze and identify the active compound in the essential oil and to identify the antimicrobial properties in cinnamon. water is the most important of raw material on our planet, for human beings, animals, plants and micro-organisms. Practically all the vital phenomena of the biosphere are related to the availability of water.water pollution which affects the rivers, the seas, the groundwater and the lakes, is the result of the wastewater without treatment or 
with a level of insufficient treatment: that causes a degradation of the ecosystem. The problem is even more serious in the case of the industrial effluents which present much more marked a toxic character. Dyes and additives used by textile industries can constitute a serious threat for the environment because their presence in water, even with very small quantities, is very visible and undesirable; consequently, their presence in the watery systems reduced the penetration of light and thus delays the photosynthetic activity.

They also have a tendency to complex the metal ions by producing a toxicity for fauna and other organizations. Consequently, the depollution of contaminated water by these chemical compounds proves to be necessary as well for environmental protection as for a possible re-use of this notconventional water and by minimizing the water losses because of this recycling.Current research is then directed towards processes of treatment low costs by using materials like clays and bentonites and other materials diatoms which can be a good alternative for the desorption of the dyes and the organic additives. These materials were already used in the developed countries where they proved reliable since they present good properties of retention. The current problem of wastewater treatment of any nature is mainly the management of the effluent generated in the purification plants. Indeed, the processes used, whether they are chemical, biological or electrochemical produce all of the considerable quantities of muds which do not find outlets and whose management is problematic.

Indeed, an uncontrolled on arable lands is regarded as very harmful for agriculture. It is thoughtthat while using the processes by Coprecipitation with materials diatoms, one can manage to regulate the problem of organic pollution in the textile industrial wastes, since the materials used are natural and do not introduce pollution. The control of water pollution is presented in the form of one of major fields of the scientific activity. The engaged activities are done by a total management of the effluents by privileging the actions of reduction of pollution, in particular by the installation of techniques such as discoloration for example. And, although the colored organic compounds constitute only one minor fraction of the organic load of wastewater, their color makes them aesthetically unacceptable. In addition, this strong coloring of water is harmful since it causes an eutrophication of water and thus an asphyxiation of the micro-organisms.

The Objective of our work is to simplify the mode of water treatment of effluents with a view:

1) To improve the results found by coagulationflocculation used by the Algerian textiles companies;

2) To apply a new method which proceeds by advanced oxidation;

3) And finally to preserve the environment of the harmful effects of the dyes remaining in the effluents like in untreated muds.

Currently, the photocatalysis is always based by titanium dioxide $\left(\mathrm{TiO}_{2}\right)$ for the experimental application.

Titanium dioxide has a big space of band: $3.0 \mathrm{eV}$ for rutile and $3.2 \mathrm{eV}$ for anatase and thus only the small fraction ( $5 \%$ ) of a solar light can be used for its photoexcitation.Consequently, of the efforts to consider were devoted the modified of $\mathrm{TiO}_{2}$ in order to prolong the band-edge of absorption the $\mathrm{TiO}_{2}$ in the obvious light irradiation ${ }^{12}$.Among them ,Fe doped with $\mathrm{TiO}_{2}$ was intensively studied the ions of $\mathrm{Fe}$ could be built in dioxide of titanium by the substitution of $\mathrm{Ti}^{4+}$ ,presenting a new force in the space of band of $\mathrm{TiO}_{2}$ which is responsible for the photoactivity of visible light ${ }^{1,3,4}$.

The principal phases of ferric oxide in kind are, in rule of crystallinity,ferrihydrite, maghemite, lepidocrocite, hematite, and goethite increasing ${ }^{5}$. The least of crystalline ferrihydrite is a brown ferric oxide with a big surface ${ }^{6}$. The ferrihydrite is also known like momentary ferric oxide phase ${ }^{7}$.The pure ferrihydrite transforms into more crystalline ferric oxides with time $^{7}$. The ferrihydrite modified diatomite (DMF) was produced the partial dissolution of diatomite by the solution of $6 \mathrm{M} \mathrm{NaOH}$ followed by the hydrolysis and oxidized of the $1 \mathrm{M}$ solution of $\mathrm{FeCl}_{2} \cdot 4 \mathrm{H}_{2} \mathrm{O}^{8}$.

The inferior content of Si could have as the consequence more crystalline ferric oxides because of the ferrihydrite transformed. 


\section{EXPERIMENTAL}

\section{Materials and methods}

Before studying the photo degradation of the dyes by the diatomite, we considered to be useful to modify our material in order to improve its properties. The details of ferrihydrite modified diatomite DMF prepared were previously reported and are recapitulated here ${ }^{9}$. The diatomite used in this study comes from the area of Sig $(50 \mathrm{Km}$ of the town of Oran) in Algeria. It is presented in the form of a powder of white color. After crushing and sifting the size of the particles of the fraction lies between 0.4-0.6 mm. This material is of great interest and has several uses such us : purification of drinking water, absorbent of the pesticides, manufacture of antibiotics, some pharmaceutical syrups and it is qualified like friendly material with to respect the environment ${ }^{10}$. The choice of this material was indicated to us by the fact that: It is very abundant it has a adsorptive affinity towards the organic heavy metals $^{11,12}$ and molecules ${ }^{13,14}$.

Chemical composition of raw diatomite DB studied was determined by $\mathrm{x}$-ray fluorescence X ( XRF) ( Philips PW 1404 ) and by electronic Micro sounder based on chemical analysis by $x$-ray fluorescence $x$ ( XRF) ( Philips PW 1404). Raw diatomite $\mathrm{DB}$ is composed of $68.017 \% \mathrm{SiO}_{2}, 19.25$ $\% \mathrm{CaCO}_{3}, 7.575 \% \mathrm{Al}_{2} \mathrm{O}_{3} ; 2.022 \% \mathrm{Fe}_{2} \mathrm{O}_{3} ; 1.241$ $\% \mathrm{MgO} ; 1.491 \% \mathrm{~K}_{2} \mathrm{O} ; 0.2 \% \mathrm{Na}_{2} \mathrm{O} ; 0.14 \% \mathrm{TiO}_{2}$; $0.038 \% \mathrm{MnO}$.

DB samples (45 g) were immersed in 300 $\mathrm{ml} 6 \mathrm{M} \mathrm{NaOH}$ solution at $90{ }^{\circ} \mathrm{C}$ for $2 \mathrm{~h}$ to partially dissolve Si [7] .The mixture was immediately added to $300 \mathrm{ml}$ of $\mathrm{FeCl}_{2} \cdot 4 \mathrm{H}_{2} \mathrm{O}$ solutions of differing concentrations ( 1,2,3 and $4 \mathrm{M}$ ) and stirred and oxidized in air at room temperature $\left(25^{\circ} \mathrm{C}\right)$ for 24 h.

The mixture was centrifuged for 30 min with the speed of 12000 rotations/min for assorted the separation. The solid obtained through centrifugation was washed with distilled water and oxidized in air at room temperature overnight. The mixture was centrifuged for $30 \mathrm{~min}$ with the speed of 15000 rotations /min for assorted the separation to remove excess $\mathrm{NaOH}$. The solid obtained through centrifugation was washed with distilled water and oxidized in air to continue the oxidation $\mathrm{Fe}(\mathrm{OH})_{2}$ and remove the excess of $\mathrm{NaOH}$ for $24 \mathrm{~h}$. The mixture was dried at $105^{\circ} \mathrm{C}$ for $24 \mathrm{~h}$. The products of this procedure were named DMF1, DMF2, DMF3 and DMF4 respectively as shown in Fig.3.

Fig.1 represents the geographical location of layer off diatomite ( Kieselguhr) the area of Sig in the west of Algeria ( from the geological point of view the area of Sig was the subject of several studies by several authors : (Perrodon, 1952; Perrodon, 1957; Thomas, 1985; Mansour, 1991; and Mansour et Al,1994 etc.). A simplified synthetic cut was raised to facilitate the study of the layers of the diatomite and the sediments associated in the diatomite formation.

Fig. 2 shows the raw diatomite DB in powder ( Kieselguhr) the area of Sig in the West of Algeria.

Fig. 3 is shown the products of modification the natural diatomite by ferrihydrite with different concentrations of $\mathrm{FeCl}_{2} \cdot 4 \mathrm{H}_{2} \mathrm{O}(1 \mathrm{M}, 2 \mathrm{M}, 3 \mathrm{M}$, and $4 \mathrm{M})$ respectively.

Fig.6. represents a mass percentages estimated for elements ( $\mathrm{Na}, \mathrm{Fe}, \mathrm{O}, \mathrm{Fe}, \mathrm{C}, \mathrm{Si}, \mathrm{Ca}, \mathrm{Mg}$ ) in DMF4 by EDAX coupled with SEM are : 50.53 $\% \mathrm{~K}, 148.36 \% \mathrm{Cl}, 0.93 \% \mathrm{Fe}, 0.18 \% \mathrm{Si}$ )

\section{Preparation of Vat Green 03 textile dye}

Fig.7 represents the molecular structure of the Indanthrene Olive Green B » Vat Green 03 » dye of textile Indanthrene Olive Green B ( C.I.Vat Green 03 ; C.I.69500) VG3 dye of textile was obtained from an industrial textile treatment Essenia »SOTEXHAM » in Oran in the West of Algeria.

Fig.8 shows the solution of the indanthrene Olive Green B ( C.I.Vat Green 03; C.I.69500) VG3 dye of textile.

The $\mathrm{pH}$ of the Vat Green 03 solution was adjusted using sodium hydroxide $(\mathrm{NaOH})$ or by hydrochloric acid $(\mathrm{HCl})$. The objective of this work is to optimize the operating conditions of the photodegradation using the titanium dioxide ( Degussa P25), with different samples ( raw diatomite DB or ferrihydrite-modified diatomite ( DMF1, and DMF4). The $\mathrm{pH}$ of the solution is an important parameter in photocatalytic processes, which not 
only plays an important role to characterize the dyes,but also determines the surface charge of the properties $\mathrm{TiO}_{2}$.

The photodecolorization of Vat Green 03 dye textile using $\mathrm{TiO}_{2}-\mathrm{DB}, \mathrm{TiO}_{2}-\mathrm{DMF} 1$, and $\mathrm{TiO}_{2}$ - DMF4 were studied in $\mathrm{pH}$ range of 4-10 and fixed the concentration of titanium dioxide $\mathrm{TiO}_{2}$ is $0.1 \mathrm{gL}^{-1}$ and $2.5 \mathrm{gL}^{-1}$ for different diatomites ( DB,DMF1, and DMF4) and thus release the dye textile (Vat Green 03), which is used as indicator of contamination at concentration of $2 \mathrm{gL}^{-1}$. The photocatalytic activity

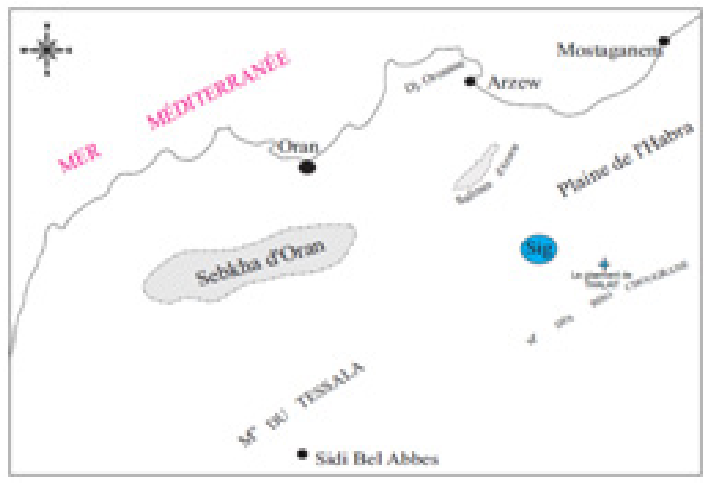

Fig. 1: Geographical location of layer off diatomite (Kieselguhr) the area of Sig « the west of Algeria » (From the geological point of view the area of Sig was the subject of several studies by several authors (Perrodon , 1952; Perrodon, 1957; Thomas, 1985; Mansour, 1991 and Mansour and Al 1994 etc). A simplified synthetic cut was raised, to facilitate the study of the layers of the diatomite and the sediments associated in the diatomite formation was determined the $\mathrm{pH}$ and the absorbance of samples every $15 \mathrm{~min}$.

\section{Pollutants studied}

The Vat Green 03 is a soluble in alkaline media to synthetic design dyeing cellulose fibers and proteins, as well as for printing cottons, as shown in Fig.8. It was provided to us by the industry textile SOTEXHAM Essenia in Oran "West of Algeria".

\section{Photodegradation test}

The aqueous solution of Vat Green 03

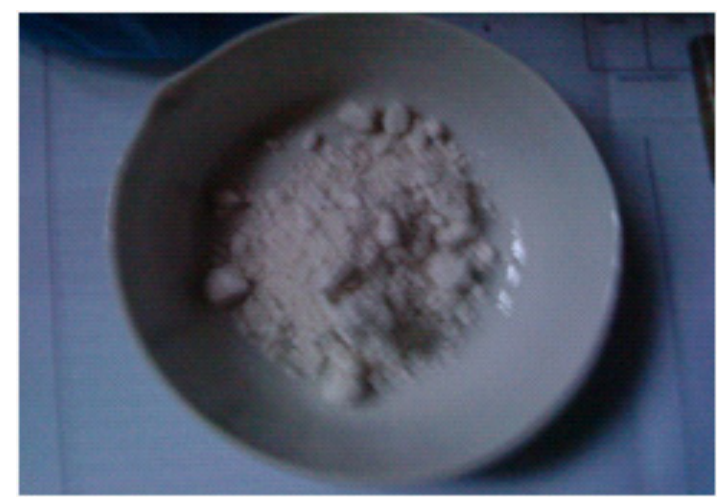

Fig. 2. The raw diatomite DB in powder (Kieselguhr) the area of Sig «the west of Algeria ».

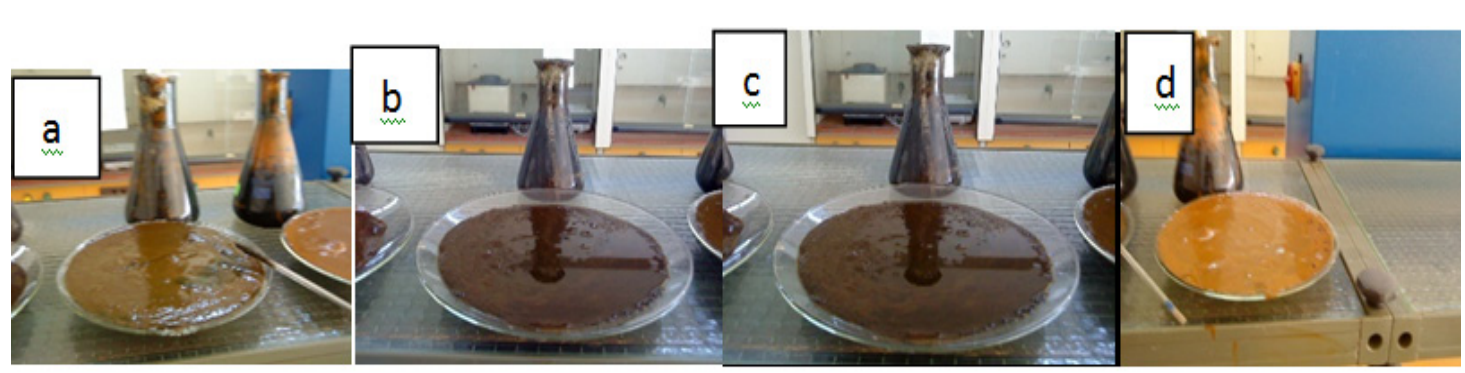

(a) : Ferrihydrite modified diatomite DMF1,(b) :Ferrihydrite modified diatomite DMF2,

(c) : Ferrihydrite modified diatomite DMF3, (d) : Ferrihydrite modified diatomite DMF4.

Fig.3. Ferrihydrite modified diatomite (DMF1, DMF2, DMF3, DMF4) respectively. 


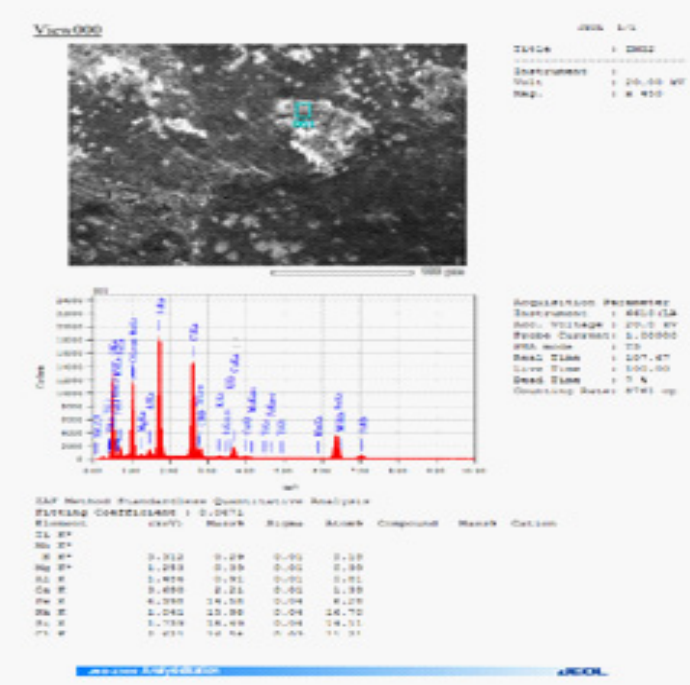

Fig. 4: Represents a mass percentages estimated for elements ( $\mathrm{Cl}, \mathrm{Si}, \mathrm{Na}, \mathrm{Fe}, \mathrm{Ca}, \mathrm{Al}, \mathrm{Mg}, \mathrm{K}$ in DMF1 by EDAX coupled with SEM are : $16.54 \% \mathrm{Cl}, 16.49 \%$ $\mathrm{Si}, 15.98 \% \mathrm{Na}, 14.58 \% \mathrm{Fe}, 2.21 \% \mathrm{Ca}, 0.91 \% \mathrm{Al}$, $0.39 \% \mathrm{Mg}, 0.29 \% \mathrm{~K})$.

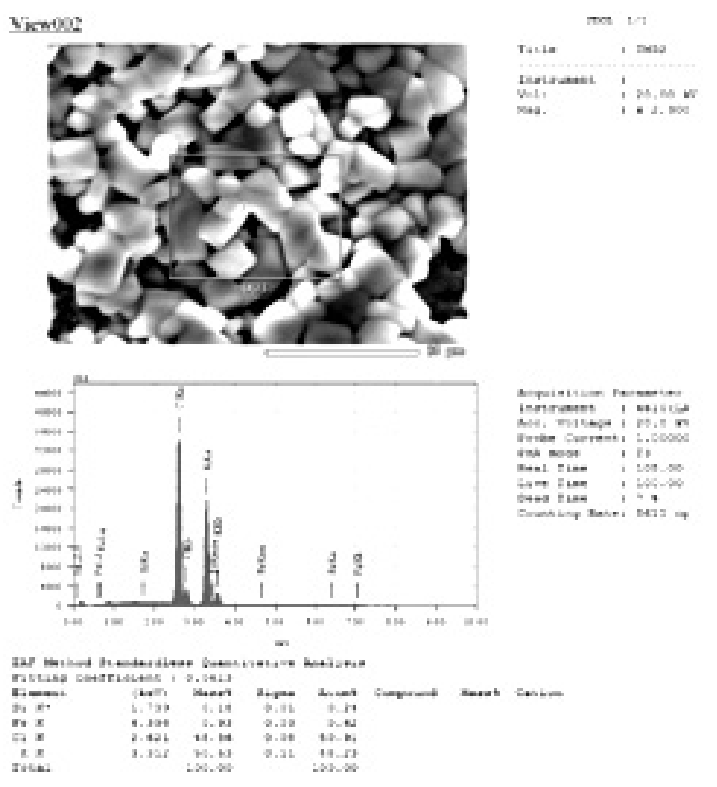

Fig.6. method standardless quantitative analysis estimated for elements ( $\mathrm{Na}, \mathrm{Fe}, \mathrm{O}, \mathrm{Fe}, \mathrm{C}, \mathrm{Si}, \mathrm{Ca}$, $\mathrm{Mg}$ ) in DMF4 by EDAX coupled with SEM are : $50.53 \% \mathrm{~K}, 148.36 \% \mathrm{Cl}, 0.93 \% \mathrm{Fe}, 0.18 \% \mathrm{Si}$ )

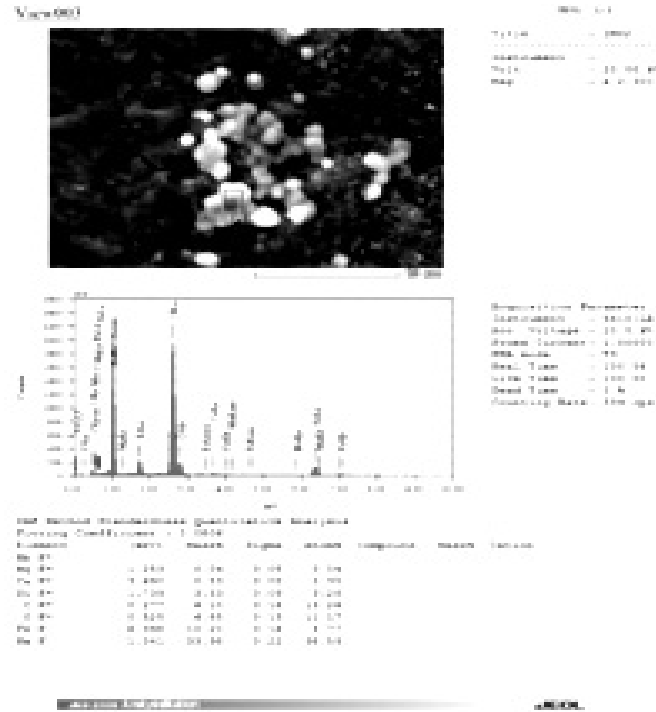

Fig. 5: Represents a mass percentages estimated for elements ( $\mathrm{Na}, \mathrm{Fe}, \mathrm{O}, \mathrm{Fe}, \mathrm{C}, \mathrm{Si}, \mathrm{Ca}, \mathrm{Mg}$ ) in DMF3 by EDAX coupled with SEM are : $33.98 \% \mathrm{Na}, \mathbf{1 0 . 2} \% \mathrm{Fe}$, $6.85 \%$ O, $6.10 \%$ C, $2.21 \% \mathrm{Ca}, 3.53 \% \mathrm{Si}, 0.53$ $\% \mathrm{Ca}, 0.04 \% \mathrm{Mg}$ ).

was prepared from a stock solution of $1 \mathrm{~g} / \mathrm{L}$ and the discharge is diluted at $2 \mathrm{mg} / \mathrm{L}$, since it is very concentrated and contains other additives (caustic soda $\mathrm{NaOH}$, sodium hydrosulfite $\mathrm{Na}_{2} \mathrm{~S}_{2} \mathrm{O}_{4}$ ) .All manipulations of the photodegradation of Vat Green 3 was conducted in a beaker of $250 \mathrm{~mL}$ with stirring at room temperature $\left[20-25^{\circ} \mathrm{C}\right]$. The using materials used are prepared from titanium dioxide concentration fixed at $0.1 \mathrm{gL}^{-1}$, and $2.5 \mathrm{gL}^{-1}$ for (raw diatomite $\mathrm{DB}$ ) , and ferrihydrite -modified diatomite ( DMF1, and DMF4), with different $\mathrm{pH}$ ( 4,7, and 10 ). They were introduced into the beaker, 200 $\mathrm{mL}$ of dye (Vat Green 03 ) concentration and $0.02 \mathrm{~g}$ of titanium dioxide $\mathrm{TiO}_{2}$ [ Degussa P25 its crystalline structure : $80 \%$ anatase $+20 \%$ rutile ] with a specific surface area is $50 \mathrm{~m}^{2} \mathrm{~g}^{-1}$; photophysics characteristic ; band gap ( $\mathrm{Eg}=3.2 \mathrm{eV}$ for anatase and $\mathrm{Eg}=3.0 \mathrm{eV}$ for rutile, with wavelength of $390 \mathrm{~nm}$ ] and $0.5 \mathrm{~g}$ of raw diatomite DB, and $0.5 \mathrm{~g}$ of ferrihydrite- modified diatomite ( DMF1, DMF4 ) to study $\mathrm{pH}$ range to 4,7 , and 10 , then the solutions were put in the dark under UV irradiation ultraviolet to take $10 \mathrm{~mL}$ of the sample every 15 min to measure the $\mathrm{pH}$.the sample is centrifuged with a speed ( 15000 rotations $/ \mathrm{min}$ ) for $30 \mathrm{~min}$ , and finally they measure the absorbance on a 
spectrophotometer model Optizen Micrometrics . As shown in Fig. 9.

The manipulation of Vat Green 03 used for each of different diatomites ( DB,DMF1, and DMF4 ) is changed under the photocatalytic reactor transilluminator with a wavelength of 365 $\mathrm{nm}$, with type Biometra, width of the lamp $15 \mathrm{~cm}$ , and length of $30 \mathrm{~cm}$, with a power is 45 Watt .In photodecolorization analysis by UV-Visible spectrophotometer model Optizen Micrometrics .As shown in Fig.10.

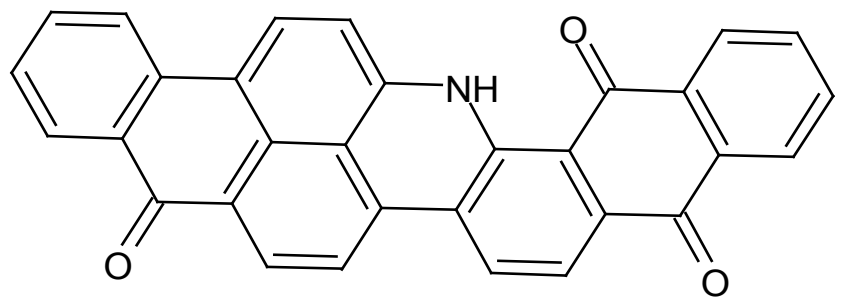

Fig . 7: Molecular structure of the Indanthrene Olive Green B « Vat Green 03 » dye of textile

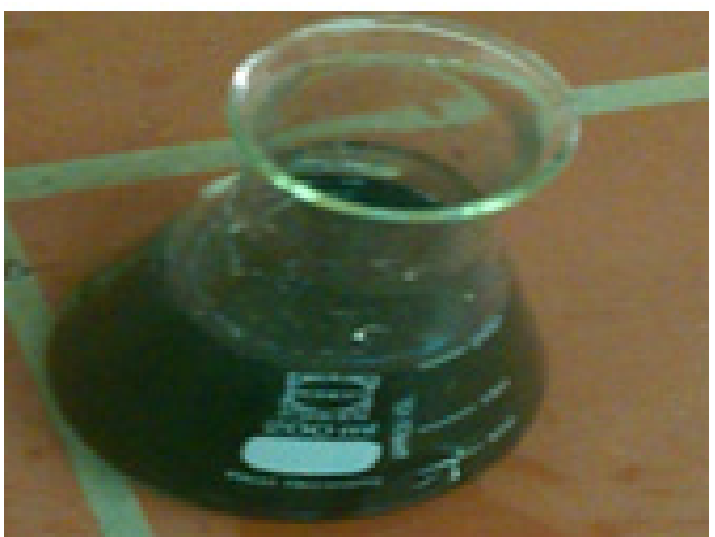

Fig. 8: The solution of The Indanthrene olive Green B(C.I.Vat Green 03 ; C.I.69500) VG3 dye of textile

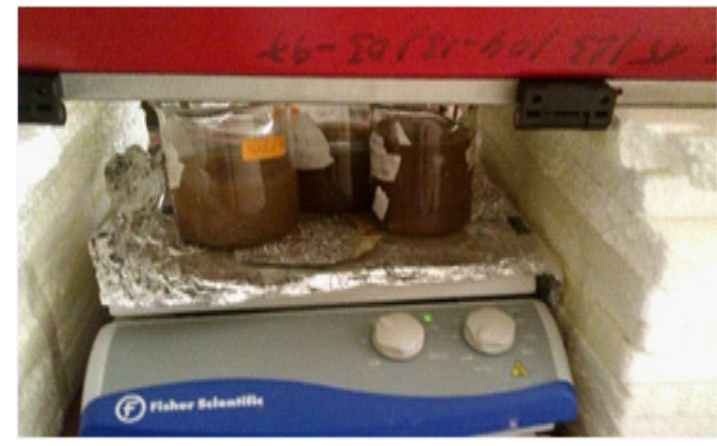

Fig. 10: Test of photodegradation ( Vat Green 03 textile ) of titanium dioxide + P25 Degussa (DB, DMF1 , DMF2 , DMF3, and DMF4 ) in the photocatalytic reactor (transilluminator)

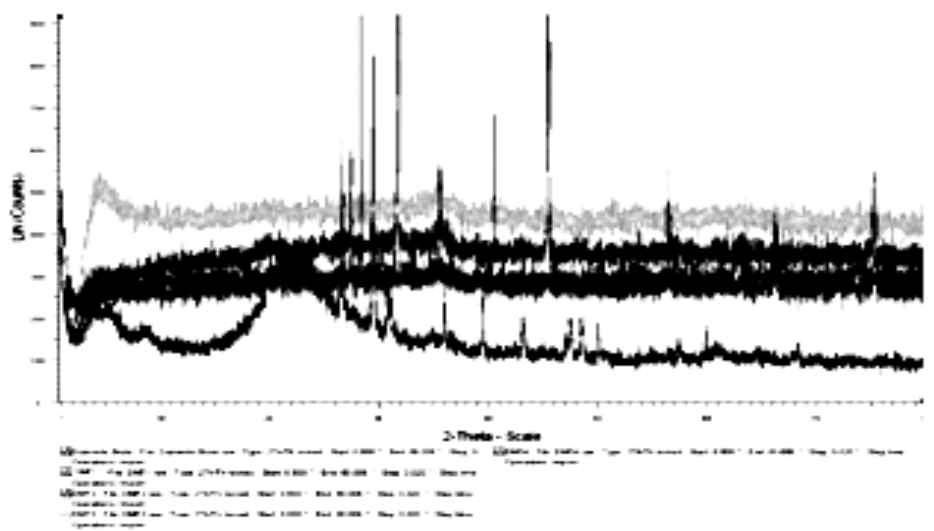

Fig. 11: X-ray diffraction patterns of DB, DMF1, DMF2, DMF3 and DMF4. DB in black - DMF1 in red - DMF2 in blue DMF 3 in green - and DMF 4 in pink 
Decolorization( \%) $=\left(\mathrm{C}_{0}-\mathrm{C}\right) / \mathrm{C}_{0}$

Here Cis the absorption of Vat Green 03 solution at irradiation time of " $\mathrm{t}$ " $\mathrm{min}$, and $\mathrm{C}_{0}$ is the initialabsorption at $\mathrm{t}=0 \mathrm{~min}$.

Characterizations of (DB,DMF1,DMF2,DMF3, and DMF4)

$\mathrm{x}$-ray diffraction (XRD) studies

The mineralogy of (DMF1, DMF2, DMF3, and DMF4) was characterized by powder x-ray diffraction (XRD) analysis using a model PW 1729 x-ray diffraction unit (Philips, Eindhoven, Netherlands) Cu Ká radiation ( $\lambda=0.1540598 \mathrm{~nm}, 50$ $\mathrm{kV}, 100 \mathrm{~mA}$ ). As shown in Fig.7.The powder sample was coated on a plate out of glass of methanol and was dried with the room temperature, then swept $1^{\circ}$ with $80^{\circ}$ (20) with the size of stage of $0.020^{\circ}$.

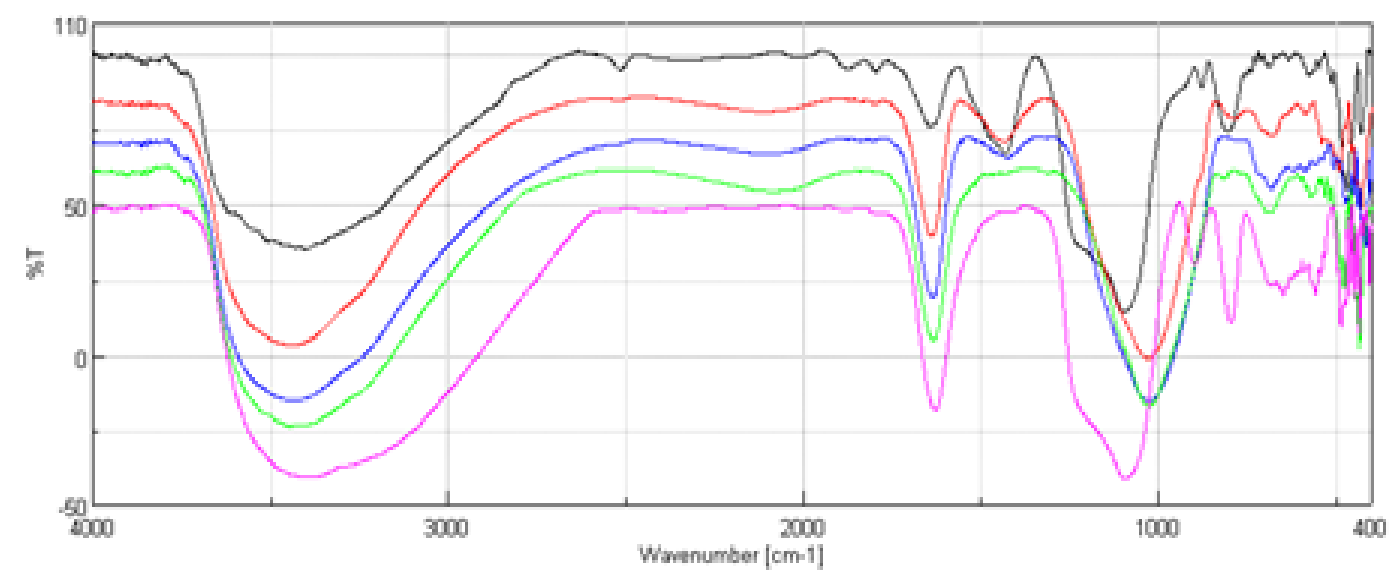

Fig. 13: FT-IR spectra of DB in black - DMF1 in red DMF2 in blue DMF 3 in green - and DMF 4 in pink

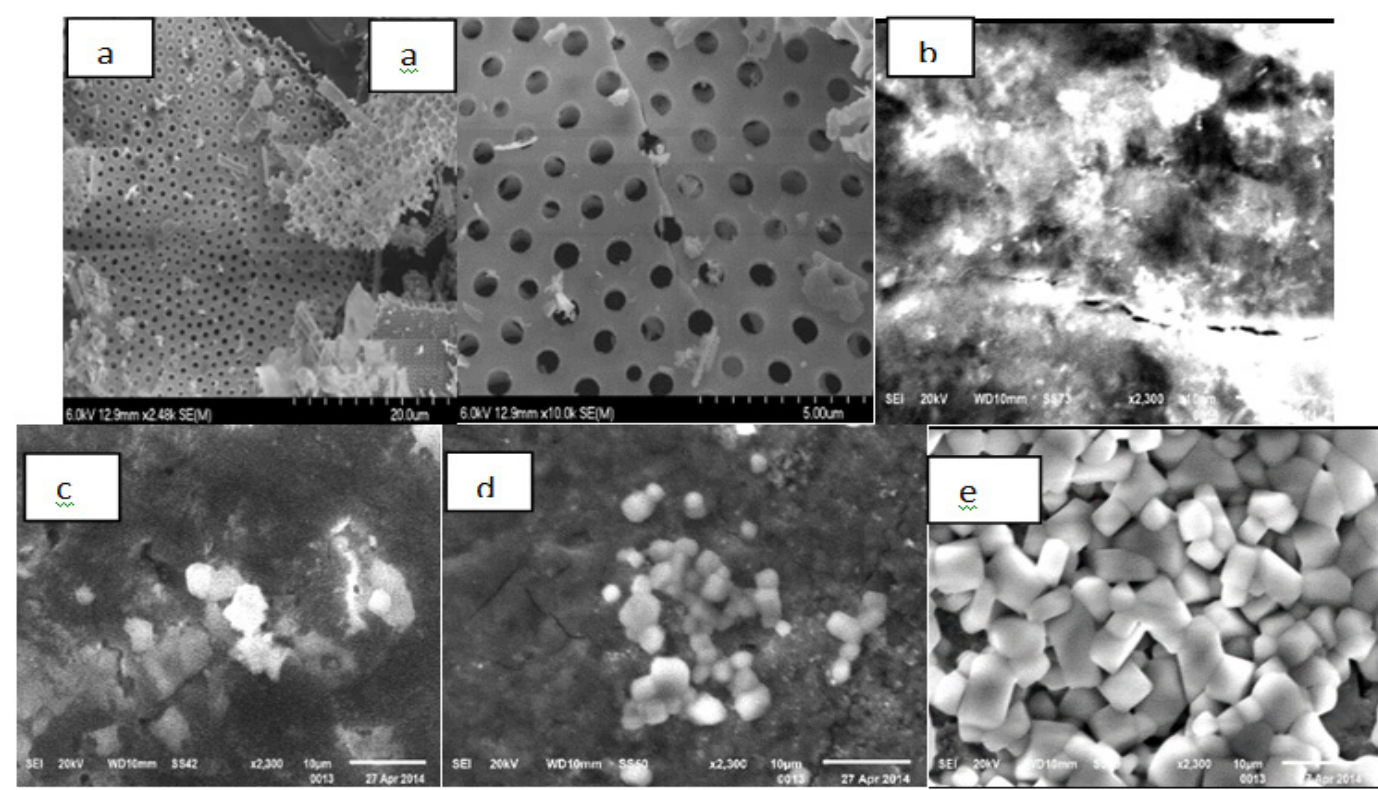

Fig. 14: Typical scanning electron micrographs for (a) Raw diatomite DB ; (b) ferrihydrite modified diatomite DMF1 ; (c) ferrihydrite modified diatomite DMF2 ; (d) ferrihydrite modified diatomite DMF3 ; and (e) ferrihydrite modified diatomite DMF4. (magnification 2300X) 


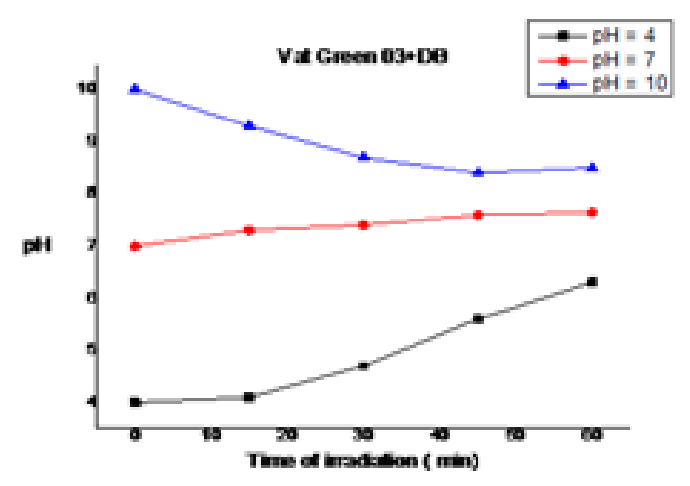

Fig.15: Effect of $\mathrm{pH}$ on the photodecolorization on Vat Green 03 using the mixture $\left(\mathrm{TiO}_{2}-\mathrm{DB}\right)$ in function the time of irradiation under UV

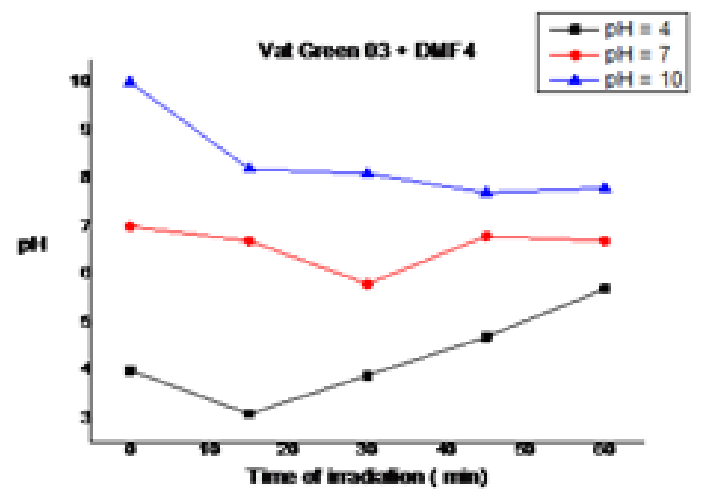

Fig.17: Effect of pH on the photodecolorization on Vat Green 03 using the mixture ( $\left.\mathrm{TiO}_{2}-\mathrm{DMF} 4\right)$ in function the time of irradiation under UV

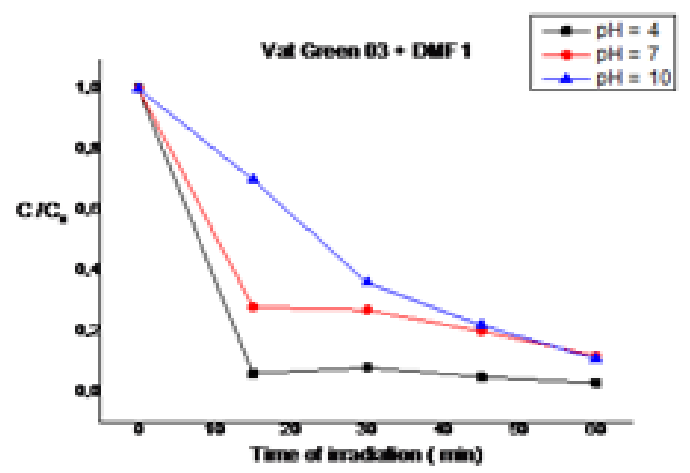

Fig.19: Degradation kinetics of Vat Green 03 textile dye under the UV lamp, using the mixture of $\left(\mathrm{TiO}_{2}+\mathrm{DMF} 1\right)$ according to the different degrees of $\mathrm{pH}$ in function the time of irradiation

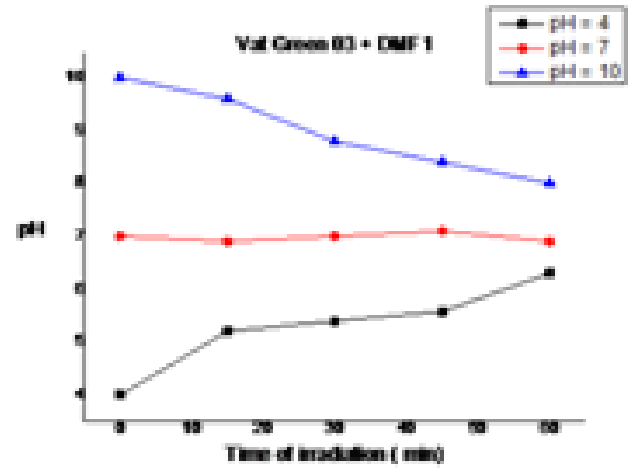

Fig.16: Effect of pH on the photodecolorization on Vat Green 03 using the mixture ( $\mathrm{TiO}_{2}-\mathrm{DMF} 1$ ) in function the time of irradiation under UV

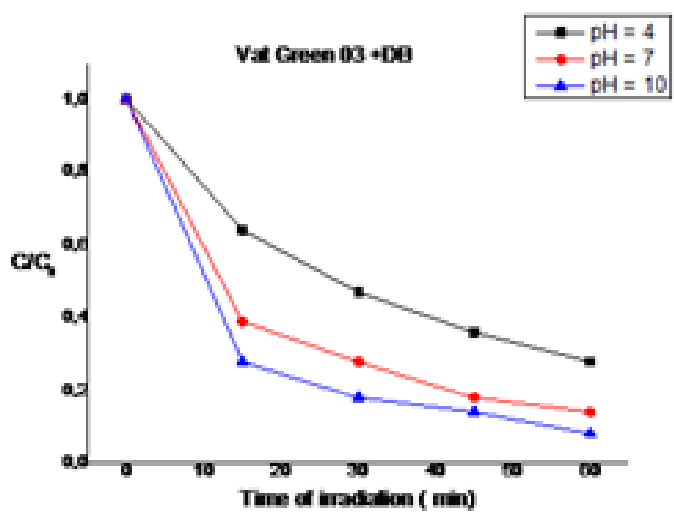

Fig.18: Degradation kinetics of Vat Green 03 textile dye under the UV lamp, using the mixture of $\left(\mathrm{TiO}_{2}+\mathrm{DB}\right)$ according to the different degrees of $\mathrm{pH}$ in function the time of irradiation

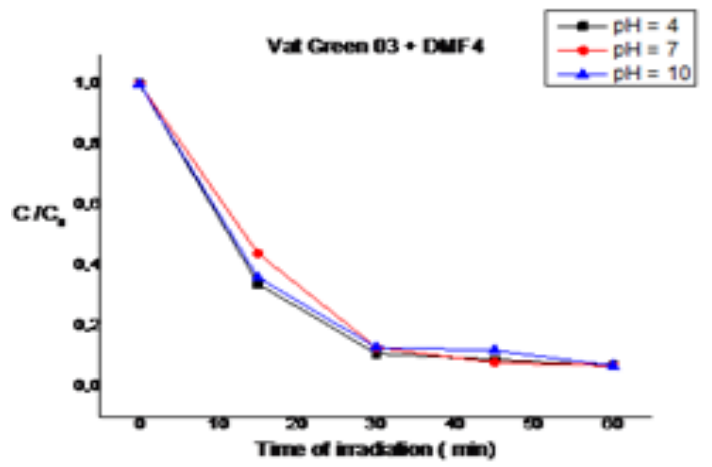

Fig. 20: Colour removal of Vat Green 03 in different $\mathrm{pH}$ 's using the mixture of $\left(\mathrm{DMF} 4+\mathrm{TiO}_{2}\right)$ in function the time of irradiation 
For the raw diatomite DB. Fig.11 represents The $\mathrm{x}$-ray diffraction powder diffraction results of raw diatomite $\mathrm{DB}$ and Ferrihydrite modified diatomite ( DMF1, DMF2, DMF3, and DMF4). The diffraction spectrogram indicates that the diatomite consists mainly of silica $\left(\mathrm{SiO}_{2}\right.$ ) and $\mathrm{CaCO}_{3}$ with smaller amonts of $\mathrm{Al}_{2} \mathrm{O}_{3}, \mathrm{Fe}_{2} \mathrm{O}_{3}, \mathrm{~K}_{2} \mathrm{O}, \mathrm{MgO}, \mathrm{Na}_{2} \mathrm{O}, \mathrm{TiO}_{2}$, and $\mathrm{MnO}$. amorphous band, represented the spectrum of raw diatomite DB ( black color ) shown in Fig.11 is probably due to the glass formation of $\mathrm{SiO}_{2}$ as the inorganic base accompanied quartz, calcite ${ }^{15}$. For Quartz ( the peaks at 2 theta $=14.5^{\circ}-17.5^{\circ}-19.5^{\circ}-21^{\circ}$ $23^{\circ}-26.5^{\circ}-36^{\circ}-39.5^{\circ}$ ) and calcite ( peaks of 2 theta $=$ $29.5^{\circ}$ to $47^{\circ}-47.5^{\circ}-48.5^{\circ}-57.5^{\circ}-60^{\circ}-64.5^{\circ}-68.5^{\circ}-77.5^{\circ}$ ) are the characteristic peaks of the raw diatomite ${ }^{16,17}$. Similar spectra were found in the characterization of a Moroccan diatomite [18]. In conclusion, the diatomite has a disorganized structure (amorphous) that reported by K.Seogluand Others ${ }^{19}$.

For DMF1. For the Quartz $\left(\mathrm{SiO}_{2}\right)$ : the peaks at 2 theta $=26.5^{\circ}-45.5^{\circ}-56.5^{\circ}-66^{\circ}-75^{\circ}$ with the interreticulars distances ( $d=3.34-1.99-1.62$ -

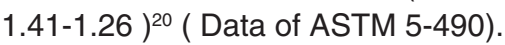

For the calcite $\left(\mathrm{CaCO}_{3}\right)$ : the peaks at 2 theta $=31.5^{\circ}-45.5^{\circ}-56.5^{\circ}-66.75^{\circ}$ with the interreticulars ( $d=2.82-1.99-1.69-1.62-1.41-1.26$ ) [20].(Data of ASTM 5-490). For the rutile $\left(\mathrm{TiO}_{2}\right)$ : the peaks at $54^{\circ}$ with the interreticular distance $\mathrm{d}=1.69$ and the peak at 2 theta $=27.5^{\circ}$ with the interreticular distance $d=3.25$ [20] (Data of ASTM 5-551). For the illite: the peak at 2 theta $=45.5^{\circ}$ with $\mathrm{d}=1.99$ [21] (Data of ASTM 9-343).For the Kaolinite: the peak at 2

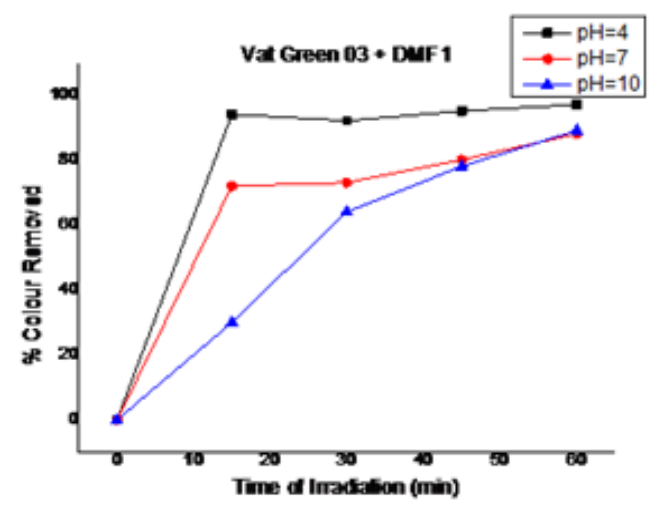

Fig. 21: Effect of pH on the photodecolorizationon Vat Green 03 textile using the mixture of $\left(\mathrm{DMF} 4+\mathrm{TiO}_{2}\right)$ in function the time of irradiation theta $=45.5^{\circ}$ with $\mathrm{d}=1.999^{21}$ (Data of ASTM 14-164). For the hematite: the peak at 2theta with $d=1.69^{20}$ (Data of ASTM 8-98).

For DMF2.For the quartz $\left(\mathrm{SiO}_{2}\right)$ : the peaks at 2 theta $=26.5^{\circ}-45.5^{\circ}-56.5^{\circ}-66^{\circ}-75^{\circ}$ with the interreticulars distances $(\mathrm{d}=3.34-1.99-1.62$ 1.40-1.26 ) ${ }^{20}$ ( Data of ASTM 5-490).

For the calcite $\left(\mathrm{CaCO}_{3}\right)$ : the peaks at 2 theta $=31.5^{\circ}-45.5^{\circ}-56.5^{\circ}-75^{\circ}$ with the interreticulars distances ( $d=2.81-1.99-1.62-1.26$ ) [20] ( Data of ASTM 5-490).For the magnetite: the peak at 2 theta $=35.5^{\circ}$ with $\mathrm{d}=2.52$ [20] (Data of ASTM 8-98). For the illite: the peak at 2 theta $=45.5^{\circ}$ with the interreticular distance $d=1.99$ [21] (Data of ASTM 9-343). For the hematite: the peak at 2 theta $=35.5^{\circ}$ with $\mathrm{d}=2.52$ [20] (Data of ASTM 8-98).For the kaolinite: the peak at 2 theta $=45.5^{\circ}$ with $\mathrm{d}=1.99$ [21] (Data of ASTM 14164). For $\mathrm{Fe}-\mathrm{TiO}_{2}$ : the peak at 2 theta $=53.5^{\circ}$ with $d=1.70$ [20] (Data of ASTM 3-781).

For DMF3.For the Quartz : the peaks at 2 theta $=20.8^{\circ}-26.5^{\circ}-45.5^{\circ}-56^{\circ}-66^{\circ}-75^{\circ}$ with the interreticulars distances ( $d=4.24-3.34-1.99-1.62$ 1.41-1.26) [20] ( Data of ASTM 17-536).For the rutile $\left(\mathrm{TiO}_{2}\right)$ : the peaks at 2 theta $=27^{\circ}$ with the interreticular distance $d=3.25$ [20] (Data of ASTM 4-551). For the calcite $\left(\mathrm{CaCO}_{3}\right)$ : the peaks at 2 theta $=31.5^{\circ}-45.5^{\circ}-75^{\circ}$ with the interreticulars distances ( $d=2.82-1.99-1.26)$ [20] (Data of ASTM 5-490). For the magnetite: the peak at 2 theta $=35.5^{\circ}$ with $\mathrm{d}=2.53$ [21].For the illite: the peak at 2 theta $=45.5^{\circ}$ with the interreticular distance $d=1.99$ [21].For the kaolinite:

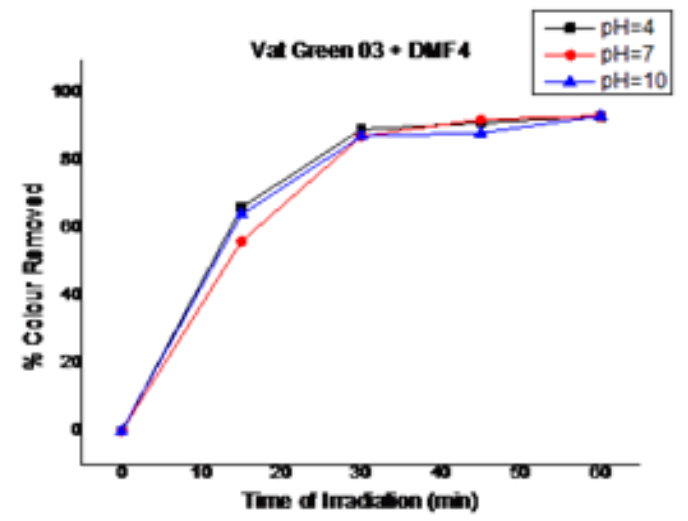

Fig. 22: Effect of pH on the photodecolorizationon Vat Green 03 textile using the mixture of $\left(\mathrm{DMF} 4+\mathrm{TiO}_{2}\right.$ ) in function the time of irradiation 
the peak at 2 theta $=45.5^{\circ}$ with $\mathrm{d}=1.99$ [21] (Data of ASTM 14-164).

For DMF4. For the quartz $\left(\mathrm{SiO}_{2}\right)$ : the peaks at 2 theta $=36.8^{\circ}-50.3^{\circ}-66.3^{\circ}-73.5^{\circ}$ with interreticulars distances $(\mathrm{d}=2.22-1.81-1.40)^{21}$. For the hematite: the peak at 2 theta $=35.5^{\circ}$ with $\mathrm{d}=2.52[21]$.For the goethite: the peak at 2 theta $=21^{\circ}$ with $\mathrm{d}=4.19^{21}$ (Data of ASTM 17-536). For the magnetite: the peaks at 2 theta $=43^{\circ}-57^{\circ}-62.5^{\circ}$ with $(d=2.08-1.60-1.47$ [20].From the maghemite: the peaks at 2 theta $=43^{\circ}$ with $d=2.08$ [20]. For the kaolinite: the peak at 2 theta $=50.3^{\circ}$ with $\mathrm{d}=1.81$ [21].For the illite: the peak at 2 theta $=36.8^{\circ}$ with the interreticular distance $d=2.45$ [21].

\section{Fourier Transform Infrared spectroscopy (FT-IR)}

FT-IR spectra of raw diatomite DB,DMF1, DMF2,DMF3, and DMF4 are realized with help of spectrophotometer using a model JASCO FT /IR4200 ( Fourier Transform Infrared Spectrometer ) between $4000 \mathrm{~cm}^{-1}$ and $400 \mathrm{~cm}^{-1}$ with the resolution of $4 \mathrm{~cm}^{-1}$. The samples are conditioned with the dispersion form in the pastille of $\mathrm{KBr}(1 / 200$ in mass) and the summarized results are shown inFig.12.

For raw diatomite DB. The large adsorption band situated at $3399 \mathrm{~cm}^{-1}$ and $1431.89 \mathrm{~cm}^{-1}$ are linked with the vibrations of ( $\mathrm{O}-\mathrm{H})$ surface and adsorbed water by the analysis of samples are proved the affinity of diatomite toward the water ${ }^{22}$. The adsorption band at $1101.15 \mathrm{~cm}^{-1}$ and 803.206 $\mathrm{cm}^{-1}$ are represented the vibration of siloxane group $(\mathrm{Si}-\mathrm{O}-\mathrm{Si})^{23}$. The adsorption band at $1645.95 \mathrm{~cm}^{-1}$ and $1101.15 \mathrm{~cm}^{-1}$ are corresponded the vibrations of $\mathrm{Si}-\mathrm{O}-\mathrm{Si}{ }^{22}$. The adsorption band at $877.452 \mathrm{~cm}^{-1}$ are corresponded the stained vibration of silanol group ${ }^{24}$. The adsorption band at $803.206 \mathrm{~cm}^{-1}$ are corresponded the vibration of $(\mathrm{Al}-\mathrm{O}-\mathrm{Si})^{25}$. Presence the characteristics bands of carbonates ions at ( $1431.89 \mathrm{~cm}^{-1} ; 740.531 \mathrm{~cm}^{-1} ; 691.355 \mathrm{~cm}^{-1} ; 877.452$ $\left.\mathrm{cm}^{-1} ; 577.576 \mathrm{~cm}^{-1}\right)^{26}$. The three adsorption bands at $\left(431.012 \mathrm{~cm}^{-1} ; 470.546 \mathrm{~cm}^{-1}\right.$; and $\left.1101.15 \mathrm{~cm}^{-1}\right)$ are attributed the vibrations of $\mathrm{Si}-\mathrm{O}-\mathrm{Si}^{24}$.

For DMF1. There is a new adsorption band at $3437.49 \mathrm{~cm}^{-1}$ corresponds the vibration of the silanol group Si-O- $\mathrm{H}^{27}$. The infrared spectrum of raw diatomite $\mathrm{DB}$. There is the disappearances of adsorption bands at $\left(2517.61 \mathrm{~cm}^{-1} ; 1874.47 \mathrm{~cm}^{-1}\right.$;
$1794.44 \mathrm{~cm}^{-1} ; 877.452 \mathrm{~cm}^{-1} ; 803.206 \mathrm{~cm}^{-1} ; 740.531$ $\mathrm{cm}^{-1}$; and $577.576 \mathrm{~cm}^{-1}$ ). There is a new adsorption band $2116.49 \mathrm{~cm}^{-1}$ corresponds the vibration of $\mathrm{Si}-\mathrm{H}$ ${ }^{28}$.The adsorption band at $1639.2 \mathrm{~cm}^{-1}$ corresponds the vibration of $\mathrm{Fe}(\mathrm{OH})_{3}{ }^{29}$. The adsorption band at $1429.36 \mathrm{~cm}^{-1}$ corresponds the vibrations of $\mathrm{CaCO}_{3}$ and $\mathrm{CaFe}\left(\mathrm{CO}_{3}\right)_{2}{ }^{30}$. The adsorption band at 783.922 $\mathrm{cm}^{-1}$ corresponds the vibration of $\mathrm{FeOOH}^{31}$. The adsorption band at $678.82 \mathrm{~cm}^{-1}$ corresponds the vibration of $\alpha-\mathrm{FeOOH}$ (goethite) ${ }^{30}$ and $\mathrm{FeOOH}^{32}$ and $\alpha-\mathrm{Fe}_{2} \mathrm{O}_{3}$ (maghemite) ${ }^{31}$. The adsorption band at $591.075 \mathrm{~cm}^{-1}$ corresponds the vibration of maghemite $\left(\alpha-\mathrm{Fe}_{2} \mathrm{O}_{3}\right)$ and magnetite $\left(\mathrm{Fe}_{3} \mathrm{O}_{4}\right)^{32}$. The adsorption band at $491.759 \mathrm{~cm}^{-1}$ corresponds the vibration of Schwertmannite ${ }^{32}$. The adsorption band at $430.048 \mathrm{~cm}^{-1}$ corresponds the vibration of $\mathrm{Si}-\mathrm{O}-\mathrm{Si}$ 24.

For DMF2. There is a new adsorption band at $3434.6 \mathrm{~cm}^{-1}$ corresponds the vibration of the silanol group $\mathrm{Si}-\mathrm{O}-\mathrm{H}^{27}$.If you compare with the infrared spectrum of raw diatomite DB. There is the disappearances of adsorption bands at ( 2517.61 $\mathrm{cm}^{-1} ; 1874.47 \mathrm{~cm}^{-1} ; 1794.44 \mathrm{~cm}^{-1} ; 877.452 \mathrm{~cm}^{-1}$; $803.206 \mathrm{~cm}^{-1} ; 740.531 \mathrm{~cm}^{-1}$; and $577.576 \mathrm{~cm}^{-1}$ ). There is a new adsorption band at $2101.06 \mathrm{~cm}^{-1}$ corresponds the vibration of $\mathrm{Si}-\mathrm{H}^{28}$. The adsorption band at $1637.27 \mathrm{~cm}^{-1}$ corresponds the vibration of $\mathrm{Fe}(\mathrm{OH})_{3}{ }^{29}$. The adsorption band at $1428.99 \mathrm{~cm}^{-1}$ corresponds the vibration of $\mathrm{CaCO}_{3}$ and $\mathrm{CaFe}\left(\mathrm{CO}_{3}\right)_{2}$ ${ }^{30}$.The adsorption band at $1025.94 \mathrm{~cm}^{-1}$ corresponds the vibrations of $\mathrm{Fe}(\mathrm{OH})_{3}$ and $\mathrm{FeOOH}^{31}$. The adsorption band at $679.785 \mathrm{~cm}^{-1}$ corresponds the vibration of goethite $\left(\alpha-\mathrm{Fe}_{2} \mathrm{O}_{3}\right)$ and magnetite $\mathrm{Fe}_{3} \mathrm{O}_{4}$ ${ }^{32}$. The adsorption band at $475.787 \mathrm{~cm}^{-1}$ corresponds the vibration of hematite $\left(\alpha-\mathrm{Fe}_{2} \mathrm{O}_{3}\right)^{32}$. The adsorption band at $415.585 \mathrm{~cm}^{-1}$ corresponds the vibration of akaganeite $(\alpha-\mathrm{FeOOH})^{32}$.

For DMF3. There is a new adsorption band at $3444.24 \mathrm{~cm}^{-1}$ corresponds the vibration of silanol group $\mathrm{Si}-\mathrm{O}-\mathrm{H}^{27}$. If you compare with the infrared spectrum of raw diatomite DB. There is the disappearances of adsorption bands at $(2517.61$ $\mathrm{cm}^{-1} ; 1874.47 \mathrm{~cm}^{-1} ; 1794.44 \mathrm{~cm}^{-1} ; 877.452 \mathrm{~cm}^{-1}$; $803.206 \mathrm{~cm}^{-1} ; 740.531 \mathrm{~cm}^{-1} ; 1645.95 \mathrm{~cm}^{-1} ; 1431.89$ $\mathrm{cm}^{-1} ; 1101.15 \mathrm{~cm}^{-1} ; 691.355 \mathrm{~cm}^{-1}$ ). There is a new adsorption band at $1633.41 \mathrm{~cm}^{-1}$ corresponds the vibration of $\mathrm{Fe}(\mathrm{OH})_{3}$ and $\mathrm{FeOOH}^{31}$. The adsorption band at $683.642 \mathrm{~cm}^{-1}$ corresponds the vibration 
of goethite $(\alpha-\mathrm{FeOOH})^{29}$. The adsorption band at $572.755 \mathrm{~cm}^{-1}$ corresponds the vibration of maghemite ${ }^{32}$. The adsorption band at $479.224 \mathrm{~cm}^{-1}$ corresponds the vibration of hematite $\left(\alpha-\mathrm{Fe}_{2} \mathrm{O}_{3}\right)$ [32]. The adsorption band at $434.869 \mathrm{~cm}^{-1}$ corresponds the vibration of $\mathrm{Si}-\mathrm{O}-\mathrm{Si}^{24}$.

For DMF4. There is a new adsorption band at $3415.31 \mathrm{~cm}^{-1}$ corresponds the vibration of silanol group Si-O-H $\mathrm{H}^{29}$. The adsorption band at $1629.55 \mathrm{~cm}^{-1}$ corresponds the vibration of $\mathrm{Fe}(\mathrm{OH})_{3}$ group $^{29}$.If you compare with infrared spectrum of raw diatomite DB .There is the disappearances of adsorption bands at $\left(2517.61 \mathrm{~cm}^{-1} ; 1874.47 \mathrm{~cm}^{-1} ; 1794.44 \mathrm{~cm}^{-1} ; 877.452\right.$ $\mathrm{cm}^{-1} ; 803.206 \mathrm{~cm}^{-1} ; 803.206 \mathrm{~cm}^{-1} ; 740.531 \mathrm{~cm}^{-1}$; $1645.95 \mathrm{~cm}^{-1} ; 1431.89 \mathrm{~cm}^{-1} ; 1101.15 \mathrm{~cm}^{-1} ; 691.355$ $\left.\mathrm{cm}^{-1} ; 577.576 \mathrm{~cm}^{-1} ; 470.546 \mathrm{~cm}^{-1} ; 431.012 \mathrm{~cm}^{-1}\right)$. The adsorption band at $1093.44 \mathrm{~cm}^{-1}$ corresponds the vibrations of $\mathrm{Fe}(\mathrm{OH})_{3}$ and $\mathrm{FeOOH}^{31}$. The adsorption band at $895.773 \mathrm{~cm}^{-1}$ corresponds the vibration of $\mathrm{FeOOH}^{31}$. The adsorption band at $797.421 \mathrm{~cm}^{-1}$ corresponds the vibration of goethite $(\alpha-\mathrm{FeOOH})^{31}$. The adsorption band at $486.938 \mathrm{~cm}^{-1}$ corresponds the vibration of Schwertmannite ${ }^{32}$. The adsorption band at $434.869 \mathrm{~cm}^{-1}$ corresponds the vibration of Si-O-Si ${ }^{24}$.The adsorption band at $406.907 \mathrm{~cm}^{-1}$ corresponds the vibration of magnetite $\left(\mathrm{Fe}_{3} \mathrm{O}_{4}\right)^{32}$.

\section{Scanning Electron Microscopy ( SEM)}

The diatomite was a modified surface by the $\mathrm{NaOH}$ treatment and the deposit of ferrihydrite. The SEM was used to determine the surface structure difference between raw diatomite DB and the modified diatomite by ferrihydrite (DMF1, DMF2, DMF3, and DMF4). The raw diatomite DB and ferrihydrite- modified diatomite (DMF1, DMF2, DMF3, and DMF4) were swept with the scanning electron microscope of analysis the model (JEOL JSM 6610 La, Japan). Fig.14 were exposure the raw diatomite $\mathrm{DB}$ by an electronic micrograph, there are two principal types of shoes in the diatoms:(1) Central, with veins radiating of a ring; (2) pennate, with veins being prolonged outside on the two sides of a longitudinal element (Round et Al., 1990). It can be seen that the raw diatomite obtained starting from layer of Sig in the west of Algeria includes understands mainly the central particles of diatom, and contains little pennate particles of diatom ${ }^{33}$. The central particles of diatom have a diameter of approximately 5-20 micrometers and the thickness of several microns. The pennate particles of diatom have a length of approximately 12 micrometers. The micrograph proves that the diatomite has a porous structure and a great empty volume.It can imply the micrograph of SEM in Fig. 14 can imply that the high porosity is mainly caused by many skeletal pores in particles of diatom and the pores interparticles between the particles of diatoms ${ }^{34}$. The micrograph of SEM of raw diatomite $\mathrm{DB}$ and ferrihydrite modified diatomite (DMF1, DMF2, DMF3, and DMF4) indicates that the raw diatomite $D B$ has a frustules modified surface and the original geometry of the pores is destroyed by the treatment of $\mathrm{NaOH}$ and the deposit of ferrihydrite (Fig.14). At the beginning, the colloidal of ferrihydrite of size is $2-5$ nanometers and the micropore is deposited ( $>50$ nanometers) and the larger of mesopores is ( $>7$ nanometers) of diatomite ${ }^{35}$. After being entirely deposited in the pores of diatomite, the additional aggregates of ferrihydrite on the surface of the diatomite particles en large surface because the formation of salt $\mathrm{KCl}$ in DMF1 and DMF4 as a crystals formed (Fig.14).

\section{Measurement of pH}

Fig. 15 represents the effect of $\mathrm{pH}$ on the photodecolorization on Vat Green 03 using the mixture $\left(\mathrm{TiO}_{2}-\mathrm{DB}\right)$ in function the time of irradiation under UV .

Fig.16 represents the effect of $\mathrm{pH}$ on the photodecolorization on Vat Green 03 using the mixture $\left(\mathrm{TiO}_{2}-\mathrm{DMF} 1\right)$ in function the time of irradiation under UV.

Fig. 17 represents the effect of $\mathrm{pH}$ on the photodecolorization on Vat Green 03 using the mixture ( $\left.\mathrm{TiO}_{2}-\mathrm{DMF} 4\right)$ in function the time of irradiation under UV.

The potential of hydrogen $(\mathrm{pH})$ of Vat Green 3 with different samples (DB, DMF1, and DMF4) tend toward neutral because they have the precipitate after $60 \mathrm{~min}$ : white colour for DB, brown green colour for DMF1, and dark brown for DMF4 because they have the reactions between the vat green 03 dye textile and the different samples (DB, DMF1, andDMF4).

\section{Kinetics of photodegradation}

Fig.18 shows the degradation kinetics of 
Vat Green 03 textile dye under the UV lamp, using the mixture of $\left(\mathrm{TiO}_{2}+\mathrm{DB}\right)$ according to the different degrees of $\mathrm{pH}$ in function the time of irradiation .

For $\left(\mathrm{DB}+\mathrm{TiO}_{2}\right) \cdot$ At $60 \mathrm{~min}$ of reaction, It was found that increase of solution $\mathrm{pH}$ from 4 to 10 increased the decolorizationeffieciency.

Fig.19 shows the degradation kinetics of Vat Green 3 textile under the UV lamp, using the mixture of $\left(\mathrm{TiO}_{2}+\mathrm{DMF} 1\right)$ according to the different degrees of $\mathrm{pH}$ in function the time of irradiation .

For $\left(\mathrm{DMF} 1+\mathrm{TiO}_{2}\right)$. At 60 min of reaction, It was found that increase of solution $\mathrm{pH}$ from 4 to 10 increased the decolorizationeffieciency. Fig.19 represents the degradation kinetics of Vat Green 3 textile under the UV lamp, using the mixture of $\left(\mathrm{TiO}_{2}\right.$ + DMF4) according to the different degrees of $\mathrm{pH}$ in function the time of irradiation.

For $\left(\mathrm{DMF} 4+\mathrm{TiO}_{2}\right)$. At 60 min of reaction, It was found that increase of solution $\mathrm{pH}$ from 4 to 10 increased the decolorizationeffieciency.

Effect of irradiation time and reaction kinetics on photocatalytic degradation of Vat Green 03 textile dye

Fig.20 shows the colourremoval of Vat Green 03 in different pH's using the mixture (DB+ $\mathrm{TiO}_{2}$ ).

Decolourisation rate of Vat Green 03 textile dye in different in different pH's using the mixture $\left(\mathrm{DB}+\mathrm{TiO}_{2}\right)$ are shown in Fig.16.At $60 \mathrm{~min}$ of reaction, it was verified that in $\mathrm{pH}=10$, there was a better colour remove about $92 \%$. It was observed that the Vat Green 03 textile dye degradation has $\mathrm{pH}$ dependency, the better results are in pH's 10,7 \& 4

Fig.21 shows the colourremoval of Vat Green 03 in different $\mathrm{pH}$ 's using the mixture $\quad(\mathrm{DMF} 1+\mathrm{TiO}$ ).Decolourisation rate of Vat Green 03 textile dye in different in different pH's using the mixture (DMF1+ $\mathrm{TiO}_{2}$ ) are shown in Fig.21. At 60 min of reaction, it was verified that in $\mathrm{pH}=4$, there was a better colour remove about $97 \%$. It was observed that the Vat Green 03 textile dye degradation has $\mathrm{pH}$ dependency, the better results are in pH's 4,10,and 7.
Fig.22 shows the colourremoval of Vat Green 03 in different pH's using the mixture (DMF4 $+\mathrm{TiO}_{2}$ ). Decolourisation rate of Vat Green 03 textile dye in different in different $\mathrm{pH}$ 's using the mixture $\left(\mathrm{DMF} 4+\mathrm{TiO}_{2}\right)$ are shown in Fig.18. At $60 \mathrm{~min}$ of reaction, It was verified that in $\mathrm{pH}=10$, there was a better colour remove about $93 \%$. It was observed that the Vat Green 03 textile dye degradation has $\mathrm{pH}$ dependency, the better results are in $\mathrm{pH}$ 's 4,10 , and 7.

Discussion for the photocatalytic activity phenomena between Vat Green 03 textile dye ,(DB,DMF1,DMF2,DMF3, and DMF4), and $\mathrm{TiO}_{2}$

Ferrihydrite-modified diatomite co-doped with titanium dioxide $\left(\mathrm{TiO}_{2}\right)$ showed enhanced visiblelight photocatalytic performance towards Vat Green 03 decolorization compared to that of Degussa P25 . It is suggested that the lattice defects induced by the ferrihydrite-modified diatomite dopant with $\mathrm{TiO}_{2}$ was responsible for the visible-light photocatalytic activities of photocatalysts .It is postulated that the visible -light photocatalytic activity of doped with $\mathrm{TiO}_{2}$ is dependent upon many other factors, such as crystalline structure, particlesize,textural properties ( ie.pore structure).

Derived photocatalysts were predominantly of anatase phase with mesoporous structure ,exhibited large specific surface areas, Si-O$\mathrm{Fe}$ and $\mathrm{Ti}-\mathrm{O}-\mathrm{Fe}$ linkages were evidenced in the ferrihydrite modified diatomite doped with $\mathrm{TiO} 2$ photocatalysts. The presence of $\mathrm{Fe}$ in ferrihydrite modified diatomite ( DMF1, and DMF4) could favor the formation of surface hydroxyl groups. Then, the incorporation between ferrihydrite-modified diatomite (DMF1, and DMF4) [ Fe ions with Si] doped with $\mathrm{TiO}_{2}$ facilitated formation of surface hydroxyls groups which is another crucial factor governing the photocatalyticactivity. As concluded about the ferrihydrite-modified diatomite ( DMF1, and DMF4 ) were doped with $\mathrm{TiO}_{2}$ by the formation of new structure through bonding $\mathrm{Si}-\mathrm{O}-\mathrm{Fe}$ and $\mathrm{Ti}-\mathrm{O}-\mathrm{Fe}$ linkages which were responsible for its visiblelight photocatalytic activity. As other method ,they proposed that the ferrihydrite modified diatomite ( $\mathrm{Fe}$ ions with $\mathrm{Si}$ ) doped with titanium dioxide to substitute $\mathrm{Ti}^{4+}$ would introduce additional intragap state ( described by Zabek et al.) [36].Under visible light irradiation, excited photosensitizer ferrihydrite 
modified diatomite ( $\mathrm{Fe}$ ions with $\mathrm{Si}$ ) doped with $\mathrm{TiO}_{2}$ ) injected an electron into the conduction band (CB) of $\mathrm{TiO}_{2}$.

The electron was subsequently transferred to oxygen adsorbed on the $\mathrm{TiO}_{2}$ surface producing superoxide radical $\left(\mathrm{O}_{2}^{--}\right)$, which is one of highly reactive oxygen species that can degrade many organic compounds ${ }^{37}$ for example : dyes of textile .Two kinds of Fe impurity states located within the electronic structure of ferrihydrite modified diatomite doped with titanium dioxide have been reported : one is above the valence band (VB) due to the fact that $t_{2 g}$ level of $3 d$ orbital of $\mathrm{Fe}^{3+}$ ions lies above the VB of $\mathrm{TiO}_{2}$.the other is below $\mathrm{CB}$ because the energy level of $\mathrm{Fe} 3 \mathrm{~d}$ electrons is lower that then of $\mathrm{Ti} 3 \mathrm{~d}$ at the bottom of $\mathrm{CB} v{ }^{-40}$. Under visible light irradiation, as an electron was photoexcited from $\mathrm{Fe}^{3+}$ dopant level to the CB or from VB to this dopant level. $\mathrm{Fe}^{3+}$ was hence converted to $\mathrm{Fe}^{4+}$ according toeq $(1)^{39}$. The photogenerated $\mathrm{CB}$ electron further reacted with adsorbed $\mathrm{O}_{2}$ to form $\mathrm{O}_{2}{ }^{--}$, while $\mathrm{Fe}^{4+}$ could react with surface hydroxyl group to produce hydroxyl radical $(\mathrm{OH})$ (eq2).Meanwhile, since the energy level of $\mathrm{Fe}^{3+} / \mathrm{Fe}^{2+}$ is below the $\mathrm{CB}$ edge of $\mathrm{TiO}_{2}{ }^{38,39}, \mathrm{Fe}$ could act as a lectron sink to trap photogenerated electron and produce $\mathrm{O}_{2}$ ( eq.s. (3)-(6) $)^{39,43}$. The photoexcitedferrihydrite modified diatomite ( Fe ions with $\mathrm{Si}$ ). Doping with $\mathrm{TiO}_{2}$ generated a hole in the $\mathrm{VB}$ of $\mathrm{TiO}_{2}$ an electron in Fe dopant level, the hole could migrate to the surface leading to the formation of $\mathrm{OH}$, While $\mathrm{Fe}^{3+}$ accepted an electron to form $\mathrm{Fe}^{2+}$ (eq. (3). in this case, $\mathrm{Fe}^{3+}$ would act as hole trap due to that the energy level of $\mathrm{Fe}^{4+} / \mathrm{Fe}^{3+}$ is above the valence band edge of $\mathrm{TiO}_{2}$ (eq.7). Additionally it is possible that Visible light response could be due to change transfer transition between Fe ions ( Eq.8) ${ }^{44}$.The photocatalytic reaction could involve the mechanistic steps of Eq.s (2) and (4)-(6),however, $\mathrm{Fe}^{3+}$ dopant with high concentration could serve as recombination centers for the photogenerated electron -hole (eqs.(9) and (10)) $)^{39,45}$, leading to decrease the photocatalyst activity.

$\mathrm{Fe}^{3+} \mathrm{h} v \rightarrow \mathrm{Fe}^{4+}+\mathrm{e}^{-}$

$\mathrm{Fe}^{4+}+\mathrm{OH}^{-} \rightarrow \mathrm{Fe}^{3+}+{ }^{\cdot} \mathrm{OH}$

$\mathrm{Fe}^{3+}+\mathrm{e}^{-} \rightarrow \mathrm{Fe}^{2+}$

$\mathrm{Fe}^{2+}+\mathrm{O}_{2} \rightarrow \mathrm{Fe}^{3+}+\mathrm{O}_{2} \cdot$
$\mathrm{Fe}^{2+}+\mathrm{Ti}^{4+} \rightarrow \mathrm{Fe}^{3+}+\mathrm{Ti}^{3+}$

$\mathrm{Ti}^{3+}+\mathrm{O}_{2} \rightarrow \mathrm{Ti}^{4+}+\mathrm{O}_{2}^{-\cdot}$

$\mathrm{Fe}^{3+}+\mathrm{h}^{+} \rightarrow \mathrm{Fe}^{3+}$

$\mathrm{Fe}^{3+}+\mathrm{Fe}^{3+} \rightarrow \mathrm{Fe}^{2+}+\mathrm{Fe}^{4+}$

$\mathrm{Fe}^{4+}+\mathrm{e}-\rightarrow \mathrm{Fe}^{3+}$

$\mathrm{Fe}^{2+}+\mathrm{h}^{+}(\cdot \mathrm{OH}) \rightarrow \mathrm{Fe}^{3+}\left(+\mathrm{OH}^{-}\right)$

\section{CONCLUSION}

This work aims to test the capacity and efficiency of the raw diatomite $\mathrm{DB}$ and ferrihydrite modified diatomite (DMF1, DMF2, DMF3, and DMF4) prepared in the laboratory to industrial degradation of dyes in effluents from textile industry .In order to better understand these materials and clearly identify their morphology, the first part of the experimental work has been devoted to the characterization of these materials. The characterization of diatomite by various analytical techniques showed that diatomite is composed mainly of amorphous silica $(68.017 \%)$ and carbonates which contaminate the surface of the mask material and part of the porosity. Porous diatomite particles are more or less heterogeneous from one fragment to another. Ferrihydrite -modified diatomite leads to a significant improvement in average pore diatomite. This was probably attributed to total elimination of carbonates and impurities. The displacement of impurities decreases the specific surface area increases and the average pore diameter of the raw diatomite DB , while its possibilities as improves adsorption. The experimental results showed that $\mathrm{The}^{\mathrm{SiO}}{ }_{2}$ is the manufacturer of the blank body diatomite with $\mathrm{CaCO}_{3}$ and $\mathrm{Al}_{2} \mathrm{O}_{3}$ as the main impurities of the order of $19 \%$ at $7 \%$ sequentially from $x$-ray fluorescence (XRF).

The Comparison of the results from $x$-ray diffraction XRD show that the raw diatomite has an irregular structure at the modification of ferrihydrite. Thephotocataytic degradation kinetic depends on the $\mathrm{pH}$ of the solution of Vat Green 03, it is more important at low $\mathrm{pH} \quad(\mathrm{pH}=4)$. All these results show that The use of raw diatomite $\mathrm{DB}$ and ferrihydrite modified diatomite (DMF1, DMF2, DMF3, and DMF4),especially ( DMF1, and DMF4) offer great potential for the removal of dyes. The derived 
photocatalysts were predominantly of anatase phase with mesoporousstructure,exhibited large specific surface areas, $\mathrm{Si}-\mathrm{O}-\mathrm{Fe}$ and $\mathrm{Ti}-\mathrm{O}-\mathrm{Fe}$ linkages were evidenced in the ferrihydrite-modified diatomite doped with $\mathrm{TiO}_{2}$ photocatalysts. The presence of $\mathrm{Fe}$ in ferrihydrite-modified diatomite ( DMF1, and DMF4) could favor the formation of surface hydroxyl groups. The natural abundance of these materials low investment costs could provide a good alternative to more costly adsorbents such as activated carbon, Zeolite, alginate ...Finally, this study was designed as a major source of information processed by ferrihydrite modified diatomite.

\section{ACKNOWLEDGEMENTS}

We would also like to express our gratitude to the laboratory team LSTGP for their help and encouragement throughout completion of the article. Our sincere thanks also go to all our teachers and colleagues at Faculty of Chemistry ( USTO -MB) . Our wish also reflect our deepest recognition to those who encouraged us to finish this work by signs of friendship which we are grateful.

\section{REFERENCES}

1. Yamashita, H. ; Harada, M. Misaka,J. ;Takeusi,M. ; Ikeuchi,K. ;Anpo,M. J. Photochem. Photobio. A : Chem.2002,148, 257-261.

2. Zaleska,A. Rec. Paten. Engin.2008,2,157164.

3. Yalçin, Y.; Kiliç, M; Çinar, Z. Appl. Catal. B: Environ. 2010,99,469-477.

4. Choi,W.; Termin,A.;Hoffmann,M.R. J. Phys. Chem. Photobio. A :Chem. 2009,203, 64-71.

5. Hoffmann,M.R.; Martin,S.T.; Choi,W.Y. J. Photochem. Photobiol. A :Chem.2009,203, 64-71.

6. Schwertmann,U.; Cornell,R.M. WileyVCH,2000,2,5.

7. Rhoton, F.E.;Bigham,J.M. J. Environ. Qual. 2005,34,890.

8. Mayer,T.D.; Jarrell,W.M. Water Res.2000,34,3949.

9. Xiong,W;Peng,J. Water Res. 2008 , 42,4869.

10. Nakkad,R.; Ezbakhe,H.; Benmoussa, A.; Ajzoul,T.; El- Bakkouri,A. Journ. Internat. Therm.2005, 12,307-309.

11. Osmanlioglu, A.E. Appl. Radiat. Isot. 2007, 65,17-20.

12. Al-Degs, Y;Khraisheh,M.A.M.;Tutundji,M.F. Water Res.2001, 15,3724-3728.

13. Khraisheh,M.A.M.;Al-Ghouti,M.A.; Allen, S.J.; Ahmad, M.N. Water Res.2005,39,922-932.

14. Yang, Y.X.; Zhang, J.B.; Yang, W.M.; Wu, J.D.; Chen,R.S. Appl .Surf . Sci.2003,206,20-28.

15. Al-Degs,Y.S.;Khraisheh,M.A.M.;Tutunji,M.F. Water Res.2001,35,3724.

16. Breese,R.O.Y. Edit. Industr. Miner. Roc.1994,397-412.
17. Frolov,Y.G.;Shabanova,N.A.;Savochkina,T.V. Kolloidn. Zh.1983,45,509.

18. Yilmaz, B; Ediz,N. Cem.Concr. Compos. 2008,30,202-211.

19. Sahraoui, H.; Abouarnadasse, S.; Elkamel, K; Nadiri,A; Yacoubi,A. Ann. Chim. Sci. Mat. 2003,29.

20. Köseoglu,R.;Köksal,F.;Ciftçi,E.; Akkurt,M. J. Mol. Struct. 2005,733,151-154.

21. Tchadjié,N.L. Mémoir. Maste. Chim. Univ. Yaound.1.2012, 25.

22. Lemogna,N.P. Mémoir. D.E.A. Univ. Yaound.1.2008,75.

23. Allen,S.J.;Whitten,L.J.;Mckay,G.,Dew. Chem. Eng. Mineral. Process.1988 ,615,231-261.

24. AlGhouti M.A., Khraisheh, M.A.M.; Allen, S.J.; Ahmad, M.N. J. Environ. Manage. 2003, 69,229-238.

25. Huang,J.; Liu,Y.;Jin,Q.;Wang,X.;Yang,J. J. Hazard. Mater.2007, 143,541-548.

26. Wilkinson,J.P. U.S. Patent.1990,36, 2412.

27. Doyle,W.D. Proc. INTERMAG Conf.1987,221226.

28. Bahramiam.B.;Ardejani,F.D.;Mirkhani,V. Appl. Catalys. A:Gener.2008,345,97-103.

29. Shen.W.;et Al. Ceram. Inter.2013,39,5013-5024

Kongola. Propert. Oxid. Oxyhydroxid. Iro.1991.

31. Van Der Marel; and Beutespacher. Propert. Oxid. Oxyhydroxid. Iro.1976.

32. Cases; et al. Propert. Oxid. Oxyhydroxid. Iro. (1989, 1990, and 1993).

33. Schwertmann ;et Cornell. Iro. Oxid. Laborat. Preparat. Character.2000.

34. Stamatakis, M.G.; Fragoulis, D, Csirik, 
G.; Bedelean. I.;Pedersen,S. Cem. Concr. Compos. 2003,25,177-184.

35. Janney,D.E,;Cowley,J.M.;Buseck,P.R. Clay and Clay Miner.1990,48,111-119.

36. Round,F.E.;Crawford,R.M.;Mann,D.G. Cambr. Univ. Pres.1990.

37. Zabek, P.Z.; Kisch,H.;J. Coord. Chem. 2010,63,2715-2726.

38. Lettmann. C.; Hildenbrand, K.; Kisch,H.;Macyk,W.; Maier,.W.F. Appl. Catal. B.2001,32,215-227.

39. Choi,W.;Termin,A.;Hoffmann,M.R. J. Phys. Chem. 1994,98,13669-13679.

40. Asiltürk,M.;Sayilkan,F.;Arpac,E. J.Photochem.
Photobiol. A: Chem.2009, 203, 64-71.

41. Wu.Y.;Zhang,J.;Xiao,L.;Chen.F. Appl. Surf. Sci.2010,256, 4260-4268.

42. Cong, Y.; Zhang, J.L. ;Chen, F.; Anpo, M.; He, D.N. J. Phys. Chem. C.2007, 111,1061810623.

43. Yu,J.;Xiang,Q.;Zhou,M.Appl. Catal. B.2009, 90, 595-602.

44. Zhu,J.;Zheng,W.;He,B.;Zhang,J.;Anpo,M. J. Mol. Catal. A : Chem.2004, 216, 35-43.

45. Zhu,J.;Chen,F.; Zhang,J.;Chen,H;Anpo,M. J. Photochem. Photobiol.A : Chem. 2006, 180,196-204. 